\title{
Use of fresh osteochondral allograft in repair of distal femur after trauma
}

\author{
Drew W. Taylor*, Kyle C. Bohm, \\ Jennifer E. Taylor, Allan E. Gross
}

\begin{abstract}
Preserving the ability to maintain an active lifestyle is a major concern in the reconstruction of the knee in young patients. For the healthy individual who desires to maintain a relatively active lifestyle, fresh osteochondral allografts may serve as an alternative to total joint reconstruction. The use of fresh allografts is primarily indicated in the patient suffering from a traumatic loss of articular segments, who is too young or active for arthroplasty. In addition, fresh osteochondral allografts have a number of advantages over arthroplasty such as providing surgeons with a source of large grafts that can be fitted to replace osteochondral defects and cover the majority or entirety of articular surfaces without any donor site morbidity. In this case, a young, active patient lost a $7 \times 8 \mathrm{~cm}$ portion of their distal femur, including a large portion of the articulating surface. Using a fresh osteochondral allograft, harvested within 24 hours of donor death, a segment was fitted to match bony apposition, articular congruity, and congruity with the femoral notch and affixed with four partially threaded cancellous screws. Joint function was restored with the allograft in place, allowing the patient to delay the need for a total joint replacement.
\end{abstract}

KEYWORDS: Allograft, Osteochondral, Trauma, Joint Reconstruction, Knee

\section{INTRODUCTION}

Reconstructing the knee in young, active patients is a major challenge in orthopaedic surgery. Repair techniques for cartilage and osteochondral defects include microfracture, osteochondral autograft, osteochondral allograft, and autologous chondrocyte implantation. The use of fresh allografts is mainly indicated in the patient suffering from a traumatic loss of articular segments who is too young or active for arthroplasty. In addition, fresh osteochondral allografts have a number of advantages over arthropasty including the absence of donor site morbidity, while providing surgeons with a source of large grafts that can be fitted and sized to

*To whom correspondence should be addressed: Drew W. Taylor

600 University Avenue Toronto, ON, Canada M5G 1X5

Tel: (416) 586-4800 Ext. 8728

Email: drew.w.taylor@gmail.com replace osteochondral defects larger than $3 \mathrm{~cm}$ in diameter and $1 \mathrm{~cm}$ deep or entire articular surfaces (1). The ability to shape the allograft to fit the individual allows for the reconstruction of a wide variety and shape of osteochondral defects. Both tibial and femoral defects can be treated, and if required, the allograft meniscus can also be transplanted along with the osteochondral graft (2). Circular femoral allografts are usually put in place using press-fit technique. In instances where the allograft covers a large surface area, as in this case of a femoral condyle or tibial plateau, cortical screws can be used, especially if osteotomy realignment is necessary to unload a compartment $(3,4)$.

Allografts are provided either as frozen tissue recovered from donors and cryogenically prepared for future use or as fresh tissue recovered and immediately used. Both types are irradiated to 
eliminate the transmission of viral and bacterial infections. If harvested within 24 hours of death and preserved at 4 degrees Celcius after irradiation, fresh avascular osteochondral allografts show a $100 \%$ chondrocyte viability after 4 days $(5,6,7)$. No anti-immunogenic drugs are administered. The thick extra-cellular matrix surrounding the chondrocytes isolates them from contact with host cells (8), but if the graft is frozen in an effort to further reduce immunogenicity, chondrocyte viability is compromised $(9,10)$. After implantation chondrocytes have been shown to remain viable for the life of the allograft. Cartilage being alymphatic, aneural and avascular unlike other transplanted tissues, eliminates the concern for vascularization after implantation. Long-term chondrocyte viability has been confirmed in multiple reports including case studies after 17, 25, and 27 years $(11,12,13,14,15,16)$.

In this case report we describe the use of fresh osteochondral allografts to repair trauma to articulating surfaces, providing an alternative to treating these injuries with a prosthetic. In this way, joint function can be restored delaying the need for a total joint replacement in the young and active patient.

\section{CASE STUDY}

A 30 year old male was recreationally riding a snow mobile when he experienced a traumatic accident. The left knee was fractured severely through the anterior aspect of his distal femur in the coronal plane. A fragment of the distal femur was contaminated and lost at the scene. In addition, his quadriceps were lacerated. A repair of his quadriceps mechanism was carried out immediately following the incident, requiring a free latissimus dorsi flap for soft tissue coverage. Following the initial surgery, the patient was able to walk and bend his knee, but suffered from pain radiating to the anterior aspect of the knee. Upon examination, the wound was healing well and the previous free flap to the anterior aspect of the knee appeared healthy. Knee joint range of motion was limited to 0 to 60 degrees. Neurovascular exam was unremarkable. After examination the patient was scheduled for a fresh osteochondral allograft to correct the bone loss in the anterior femur. Pre-operative radiographs were taken to plan the operative requirements of the patient (figure 1). As the preoperative radiographs did not indicate any angular deformity in the leg on 4-foot standing views, an osteotomy was not planned. The surgery was conducted 7 months following the traumatic incident.

\section{Operative Technique}

The previous trauma and surgery with subsequent scar tissue was considered when planning the incision site. The incision was made longitudinally over the anterior distal femur, curving medially around the medial aspect of the previous latissimus dorsi graft. A medial parapatellar arthrotomy was performed. Due to the great deal of scar tissue encountered on the inferior aspect of the patella,

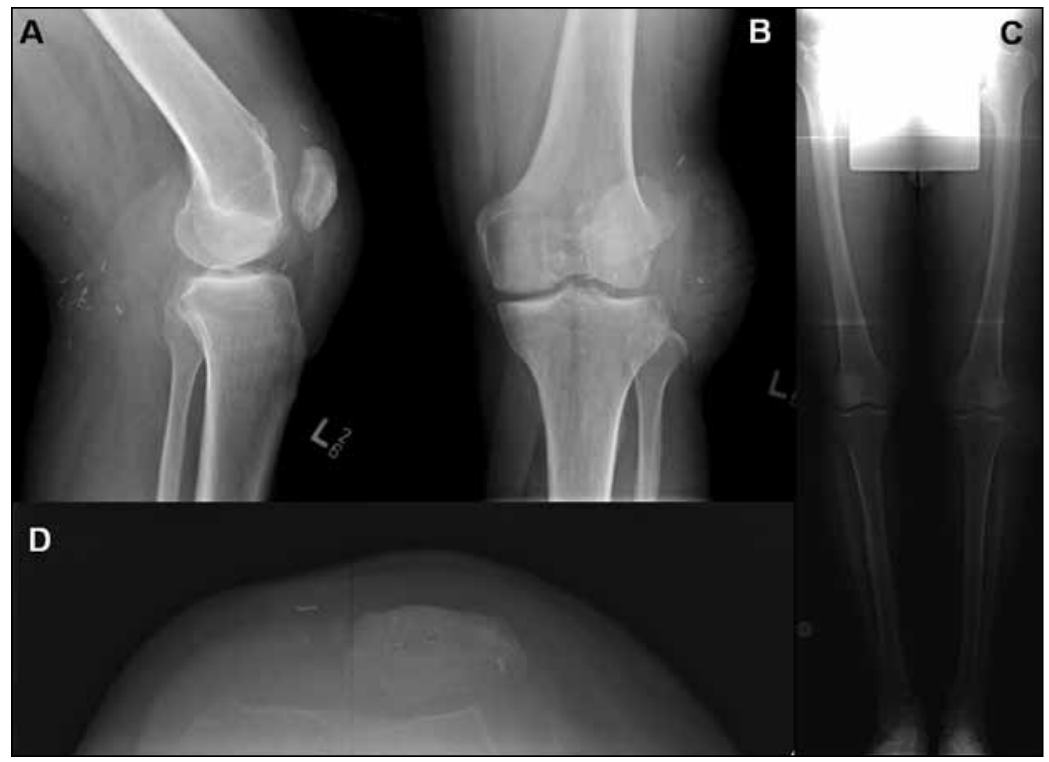

Figure 1: Preoperative $x$-rays including coronal $(A)$ and sagittal $(B)$ aspects about the left knee. Four-foot standing $x$-rays $(C)$ were also taken to evaluate joint angulation. Axial x-rays through the defect and patella were also taken to depict the defect size and location as well as the placement of the patella. 


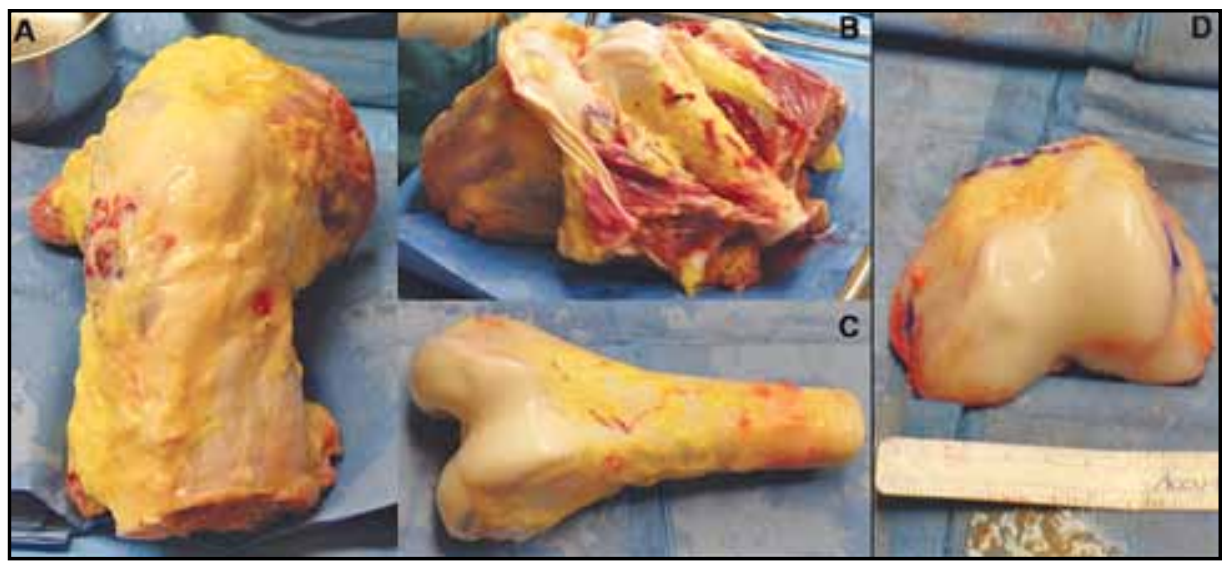

Figure 2: The preparation of the received allograft $(A)$ included the removal of soft tissue and musculature $(B)$ down to the articular surface without damaging the cartilage $(C)$. The allograft was sized to the defect and excess bone was removed using an oscillating saw (D). Any further measurements were made by re-sizing the allograft directly against the defect site and making additional adjustments with the oscillating saw.

an incision through the anterior medial third of the patellar tendon was used to gain access to the joint space. This was repaired with a Kessler stitch following the procedure.

Following the arthrotomy, scar tissue was cleared off the anterior aspect of the distal femur down to bleeding bone. The defect was measured to be $7 \mathrm{~cm}$ in the mediolateral plane, and $6 \mathrm{~cm}$ from anterior to posterior in the coronal plane beginning from the top of the femoral notch to the top of the defect. These measurements were used to model the allograft. After the removal of scar tissue, the knee was flexed to approximately 70 degrees. In this position, an oscillating saw was used to level the defect plane in order to attain a flat surface to affix the allograft flush with host bone.
The fresh osteochondral allograft was obtained according to the procedures established by the American Association of Tissue Banks (17). The allograft was irradiated with $2.5 \mathrm{Mrad}(25,000 \mathrm{~Gy})$ in the hospital bone bank, and consequently stored at -70 degrees Celsius. To maximize cartilage quality, the donor chosen was less than 30 years old. The graft was procured within 12 hours of death, excising the entire joint including the capsule and ligaments under strict aseptic precautions. Bacterial, fungal and mycobacterial cultures were taken before the joint was submersed in Ringer's solution containing $1 \mathrm{~g} / \mathrm{l}$ of cefazolin and 50,000 units/L bacitracin and sealed in a container. The container was then wrapped in sterile towels and plastic bags and stored at 4 degrees Celsius until use. The allograft

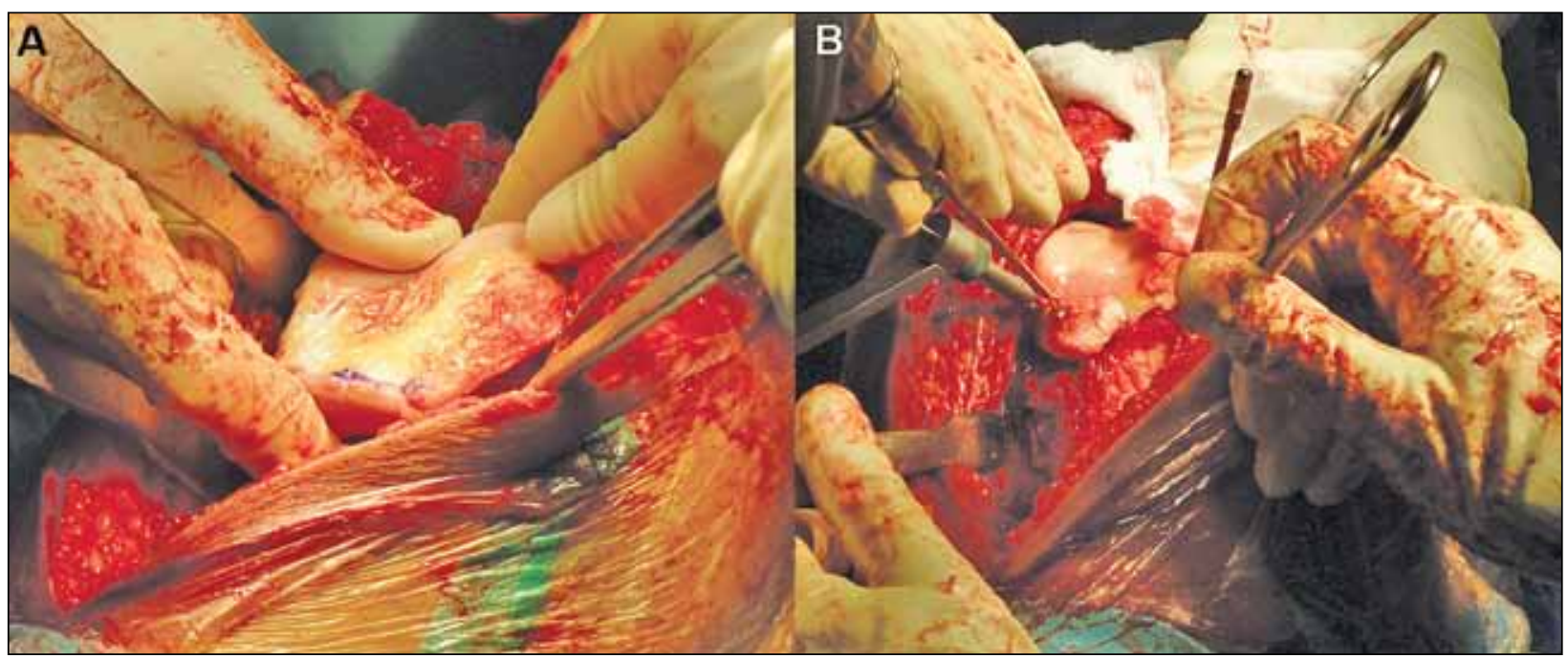

Figure 3: Once the allograft was sized against the defect site (A), ensuring that bony apposition, articular congruity, and congruity with the femoral notch had abeen achieved, the allograft was carefully affixed to the distal femur using four 6.5 mm partially threaded cancellous screws (B). 
was initially prepared on a separate table using an oscillating saw while intraoperative measurements were taken about the defect site. Outer musculature about the allograft was removed with special care given to avoid damaging the allograft articular surface (figure 2). Final adjustments were made by sizing the graft directly against the patients defect site (figure $3 \mathrm{~A}$ ). Throughout preparation of the allograft, it was irrigated with Bacitracin solution. Once the desired fit was achieved, including bony apposition, articular congruity, and congruity with the femoral notch, the graft was affixed to the distal femur using four $6.5 \mathrm{~mm}$ partially threaded cancellous screws (figure 3B). After fixation, intraoperative radiographs were obtained confirming good position. Following radiographs, tracking of the patella was physically examined with careful attention to ensure there was no lateral subluxation. The entire wound was irrigated with Bacitracin solution before closure. Again, a Kessler stitch using a 2-0 Vicryl suture was used to close the opening made in the patellar tendon. The repair held after knee flexion to 90 degrees.

\section{DISCUSSION}

Postoperative management included keeping the patient in an immobilizer, but improvements in passive range of motion upwards of 90 degrees of flexion resulted. Passive range of motion exercises were encouraged while the patient remained on site. At the time of discharge, the left lower extremity was neurovascularly intact and no evidence of infection was observed. At this time, the patient was ambulating well using crutches with

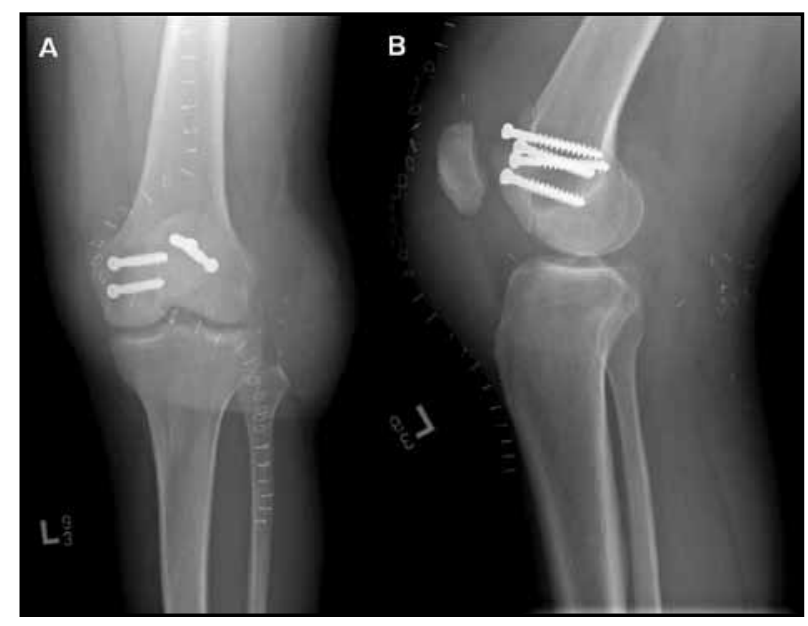

Figure 4: Postoperative $\mathrm{x}$-rays were taken at the time of surgery and as depicted here, one week after surgery before final discharge. Sagittal (A) and coronal (B) images were taken about the left knee to ensure proper placement and fixation of the allograft. Note the proper placement of the patella in the patellar groove. emphasis on avoiding weight-bearing. Another set of post-operative $\mathrm{x}$-rays confirmed the placement and attachment of the allograft before the patient returned home (figure 4). At this time, the patient began a rigorous yet conservative physiotherapy program to regain function of the left leg. Due to the severe amount of trauma inflicted on the musculature about knee joint a well planned program is of utmost importance. In cases as this, the trauma an abundance of scar tissue may make progress in knee flexion and range of motion more difficult. Our patient was young and very determined to regain full use of the leg. Despite the damage to the quadriceps and the build-up of scar tissue, he progressed very quickly regarding improvements in range of motion. One month post-op, passive range of motion had improved to 112 degrees and quadriceps muscle strength had improved greatly. The patient could fully ambulate unassisted with only a slight limp and had significant reduction in joint pain. At this time he continued physiotherapy geared towards optimizing gait and quadriceps strength. With continued physiotherapy for the soft tissue damage, further improvements allowed the patient to return to light recreational activity.

The use of fresh allografts is mainly indicated in the patient suffering from a traumatic loss of articular segments deemed too young or active for arthroplasty. Allograft has been used to treat conditions in addition to tramatic injury. The use of fresh osteochondral cadaveric allografts for conditions including unicompartmental osteoarthritis, steroid-induced avascular necrosis of the femoral condyles, osteoarthritis dissecans, and traumatic defects has shown encouraging mid- and long-term results $(18,19,20,1,21,22,23,24,25,26,27,28$, 29). These clinical evaluations have demonstrated a reduction in joint pain, allograft-host bone healing an improved weight bearing. Grafts performed secondary to trauma have the most promising results, while grafts for degenerative disease have had the worst $(25,29)$. At our institution, osteochondral allografts are not used currently for treating osteoarthritis or osteonecrosis that is steroid-induced or occurs spontaneously with inflammatory arthropathy. Patients under the age of 60 have been reported to have better results with allografts than those above (24). In addition, the use of allografts for bipolar defects across the femur and tibia have not been as successful as unipolar transplants (19). In a recent study of survival rates of fresh femoral osteochondral allografts, $74 \%$ of grafts survived at 15 years with $61 \%$ of the patients having excellent to good functional outcomes (1). Some of the failures 
included were due to the development of degenerative joint disease (osteoarthritis).

Aside for the limitation in situational use, there are a number of disadvantages for using fresh osteochondral allografts. Large shell allografts are in limited supply, and patients much wait until a cadaveric allograft becomes available (30). In addition, it is necessary to use a highly organized transplant service because of the concern for disease transmission. The risk for transmission is similar to that of homologous blood transfusion, although lower estimates have been published (31). Donor osteocytes do not survive without vascularization. The heightened immunogeneic response this may induce is not countered with immunosuppressive drugs and not considered necessary. In histopathologic analysis of failed osteoarticular shell allografts between 12 and 84 months after transplantation, no evidence of transplant rejection was detected (32). For the healthy patient, who desires to maintain relatively active lifestyle, fresh osteochondral allografts may serve as an alternative to total joint reconstruction. Here, a young, active patient lost a $7 \times 8 \mathrm{~cm}$ portion of their distal femur, including a large portion of the articulating surface. Using an allograft, joint function was restored, while allowing the patient to delay the need for a total joint replacement.

\section{REFERENCES}

1. Gross, A. E., Shasha, N., and Aubin, P. Long-term followup of the use of fresh osteochondral allografts for posttraumatic knee defects. Clin Orthop Relat Res. 2005;79-87.

2. Gross, A. E. Use of fresh osteochondral allografts to replace traumatic joint defects. 1992.

3. Gross, A. E. and Hutchison, C. R. Realignment osteotomy of the knee-part 2: proximal valgus tibial osteotomy for osteoarthritis of the varus knee. Oper Tech Sports Med. 2000;8:127-130.

4. Gross, A. E. and Hutchison, C. R. Realignment osteotomy of the knee-part 1: distal femoral varus osteotomy for osteoarthritis of the valgus knee. Oper Tech Sports Med. 2000;8:122-126.

5. Campbell, C. J., ISHIDA, H., Takahashi, H., and KELLY, F. THE TRANSPLANTATION OF ARTICULAR CARTILAGE. AN EXPERIMENTAL STUDY IN DOGS. J Bone Joint Surg Am. 1963;45:1579-1592.

6. DEPALMA, A. F., TSALTAS, T. T., and MAULER, G. G. VIABILITY OF OSTEOCHONDRAL GRAFTS AS DETERMINED BY UPTAKE OF S35. J Bone Joint Surg Am. 1963;45:1565-1578.

7. Rodrigo, J. J., Thompson, E., and Travis, C. Deep-freezing versus 4 degrees preservation of avascular osteocar- tilaginous shell allografts in rats. Clin Orthop Relat Res. 1987;268-275.

8. Langer, F., Czitrom, A., Pritzker, K. P., and Gross, A. E. The immunogenicity of fresh and frozen allogeneic bone. J Bone Joint Surg Am. 1975;57:216-220.

9. Enneking, W. F. and Mindell, E. R. Observations on massive retrieved human allografts. J Bone Joint Surg Am. 1991;73:1123-1142.

10. Stevenson, S., Dannucci, G. A., Sharkey, N. A., and Pool, R. R. The fate of articular cartilage after transplantation of fresh and cryopreserved tissue-antigen-matched and mismatched osteochondral allografts in dogs. J Bone Joint Surg Am. 1989;71:1297-1307.

11. Convery, F. R., Akeson, W. H., Amiel, D., Meyers, M. H., and Monosov, A. Long-term survival of chondrocytes in an osteochondral articular cartilage allograft. A case report. J Bone Joint Surg Am. 1996;78:1082-1088.

12. Czitrom, A. A., Keating, S., and Gross, A. E. The viability of articular cartilage in fresh osteochondral allografts after clinical transplantation. J Bone Joint Surg Am. 1990;72:574581.

13. Jamali, A. A., Hatcher, S. L., and You, Z. Donor cell survival in a fresh osteochondral allograft at twenty-nine years. A case report. J Bone Joint Surg Am. 2007;89:166-169.

14. Maury, A. C., Safir, O., Heras, F. L., Pritzker, K. P., and Gross, A. E. Twenty-five-year chondrocyte viability in fresh osteochondral allograft. A case report. J Bone Joint Surg Am. 2007;89:159-165.

15. McGoveran, B. M., Pritzker, K. P., Shasha, N., Price, J., and Gross, A. E. Long-term chondrocyte viability in a fresh osteochondral allograft. J Knee Surg. 2002;15:97-100.

16. Oakeshott, R. D., Farine, I., Pritzker, K. P., Langer, F., and Gross, A. E. A clinical and histologic analysis of failed fresh osteochondral allografts. Clin Orthop Relat Res. 1988;283294.

17. Tomford, W. W., Mankin, H. J., Friedlaender, G. E., Doppelt, S. H., and Gebhardt, M. C. Methods of banking bone and cartilage for allograft transplantation. Orthop Clin North Am. 1987;18:241-247.

18. Aubin, P. P., Cheah, H. K., Davis, A. M., and Gross, A. E. Long-term followup of fresh femoral osteochondral allografts for posttraumatic knee defects. Clin Orthop Relat Res. 2001;S318-S327.

19. Chu, C. R., Convery, F. R., Akeson, W. H., Meyers, M., and Amiel, D. Articular cartilage transplantation. Clinical results in the knee. Clin Orthop Relat Res. 1999;159-168.

20. Ghazavi, M. T., Pritzker, K. P., Davis, A. M., and Gross, A. E. Fresh osteochondral allografts for post-traumatic osteochondral defects of the knee. J Bone Joint Surg Br. 1997;79:1008-1013.

21. McDermott, A. G., Finklestein, J. A., Farine, I., Boynton, E. L., MacIntosh, D. L., and Gross, A. Distal femoral varus osteotomy for valgus deformity of the knee. J Bone Joint Surg Am. 1988;70:110-116. 
22. Shasha, N., Krywulak, S., Backstein, D., Pressman, A., and Gross, A. E. Long-term follow-up of fresh tibial osteochondral allografts for failed tibial plateau fractures. J Bone Joint Surg Am. 2003;85-A Suppl 2:33-39.

23. Bayne, O., Langer, F., Pritzker, K. P., Houpt, J., and Gross, A. E. Osteochondral allografts in the treatment of osteonecrosis of the knee. Orthop Clin North Am. 1985;16:727-740.

24. Beaver, R. J., Mahomed, M., Backstein, D., Davis, A., Zukor, D. J., and Gross, A. E. Fresh osteochondral allografts for post-traumatic defects in the knee. A survivorship analysis. J Bone Joint Surg Br. 1992;74:105-110.

25. Convery, F. R., Meyers, M. H., and Akeson, W. H. Fresh osteochondral allografting of the femoral condyle. Clin Orthop Relat Res. 1991;139-145.

26. Flynn, J. M., Springfield, D. S., and Mankin, H. J. Osteoarticular allografts to treat distal femoral osteonecrosis. Clin Orthop Relat Res. 1994;38-43.

27. Gross, A. E., Beaver, R. J., and Mohammed, M. N. Fresh Small Fragment Osteochondral Allografts Used for PostTraumatic Defects in the Knee Joint. 1992;123-141.
28. Mahomed, M. N., Beaver, R. J., and Gross, A. E. The longterm success of fresh, small fragment osteochondral allografts used for intraarticular post-traumatic defects in the knee joint. Orthopedics. 1992;15:1191-1199.

29. Meyers, M. H., Akeson, W., and Convery, F. R. Resurfacing of the knee with fresh osteochondral allograft. J Bone Joint Surg Am. 1989;71:704-713.

30. Shasha, N., Aubin, P. P., Cheah, H. K., Davis, A. M., Agnidis, Z., and Gross, A. E. Long-term clinical experience with fresh osteochondral allografts for articular knee defects in high demand patients. Cell Tissue Bank. 2002;3:175-182.

31. Buck, B. E., Malinin, T. I., and Brown, M. D. Bone transplantation and human immunodeficiency virus. An estimate of risk of acquired immunodeficiency syndrome (AIDS). Clin Orthop Relat Res. 1989;129-136.

32. Kandel, R. A., Gross, A. E., Ganel, A., McDermott, A. G., Langer, F., and Pritzker, K. P. Histopathology of failed osteoarticular shell allografts. Clin Orthop Relat Res. 1985;103-110.

Drew W. Taylor ( $\mathrm{PhD}(2010), \mathrm{MS})$ is currently in a $\mathrm{PhD}$ program in Biomedical Engineering at the University of Toronto. He received his B.S. and M.S. in Molecular, Cellular, and Developmental Biology from the University of Michigan.

Kyle C. Bohm (MD(2011), BS) is currently in his third year of Medical School at the University of Michigan. He received his B.S. in Kinesiology from the University of Michigan.

Jennifer E. Taylor (MS(2010), BA, CPT) is currently working in Strength and Conditioning in the Athletic Department at the University of Michigan while completing her Masters in Exercise Physiology. She completed her Bachelor's degree in Kinesiology at the University of Michigan.

Allan E. Gross (MD, FRCSC, O.Ont) is an Orthopaedic Surgeon at Mount Sinai Hospital specializing in lower extremity reconstruction, with a particular interest in revision arthroplasty of the hip and knee. He holds the Bernard Ghert Chair in Lower Extremity Reconstructive Surgery and also serves as a professor in the Department of Surgery at the University of Toronto. 